\title{
Emergy based sustainability evaluation for Shandong province, China
}

\author{
Yanliang Liu, ${ }^{1, a}$ \\ ${ }^{1}$ College of Environmental Science and Engineering, Tongji University, Shanghai, 200092, China
}

\begin{abstract}
With the development of urbanization, urban system has become the center of human habitation, business activities and economic growth in the world. With the influx of daring population into the city, human activities in the city will become more frequent, and the problems of environmental pollution and resource depletion will affect the sustainable development of the city. Therefore, this paper uses emergy theory of eco economic system to analyze the sustainability of urban metabolic process in Shandong province from 2008 to 2018. The results show that the total energy consumption of Shandong Province is gradually increasing from $1.85 \times 10^{24}$ sej in 2008 to $3.48 \times 10^{24}$ sej in 2018 . However, the emergy sustainability indices show that the sustainability of Shandong province is gradually decreasing. This is mainly because the development of Shandong province depends on the development of local resources, which makes the economic development of the cities cause greater pressure on the natural environment.
\end{abstract}

\section{Introduction}

Urbanization has played a positive role in promoting China's economic development and improving people's living standards. However, with the rapid urbanization in China, it also has a huge pressure on the ecological environment and hindered the sustainable development of the city. Urban sustainable development is related to the security and prosperity of the country [1]. The main basis to measure the efficiency of urban management is to establish the evaluation methods and indicators of urban sustainable development, quantitatively track the development path of the city, compare the current situation and trend of urban sustainable development at home and abroad, and diagnose the problems existing in resources, environment, social economy and other aspects of urban development [2]. Therefore, it is of great significance to systematically analyze and evaluate the sustainable development status and future trend of Chinese cities for guiding the high-quality development of cities and social economy.

The concept of urban sustainable development includes the sustainable development of economic dimension, social dimension and natural dimension [3]. Economic development is the means to realize social progress and natural resources utilization. Resources and environment are the necessary material basis and living space for the survival and development of urban residents in their daily life [4]. At present, studies have recognized that the sustainable development of cities needs to consider the environmental, social and economic aspects, and evaluate the sustainability of different cities. But these methods are not very clear about the relationship between environment, society and economy. Moreover, the differences of material flow, energy flow and money flow in the three subsystems make it impossible to add them together in sustainability assessment. Compared with other environmental accounting methods, emergy analysis method has more obvious advantages. On the one hand, this method can convert all different types of energy, resources, products, and even labour and services, such as incomparable and male-accounted items, into a unified unit of measurement. This is the calculation of environmental load and environmental economic performance. Evaluation provides a new way of thinking and can be used to determine the environmental value of marketized and non-marketed resources, services, and commodities in the emergy required for a given product or service. On the other hand, emergy theory is based on the law of material and energy flow in the biosphere. This method is based on the principle of energetics, system theory and system ecology. Emergy is more convincing in reflecting the real value of natural resources and ecological services. Emergy analysis is not only an important method of environmental accounting, but also an important tool for system analysis and evaluation because of its detailed analysis of material flow and energy transfer. It allows quantifying the environmental workload supporting each traffic or storage, and evaluating each resource from the host side, rather than just based on human preferences and market contingency. Therefore, this study uses emergy method to calculate the input and output of urban ecosystem, and establishes indicators to evaluate the sustainability of the city. 


\section{Methods and data}

\subsection{Accounting method}

Based on energetics and system ecology, American ecologist H.T.Odum established emergy theory [5]. The theory explains how the system uses energy to organize effectively. Emergy is based on the second law of thermodynamics, and establishes a common unit of measurement. The development of economic activities is not only restricted by economic rules, but also restricted by ecology. This concept is to integrate economics and ecological science with energy. In terms of accounting method, every product on the earth is transmitted through a series of energy. Finally, it is found that it is driven by three basic resources, namely solar energy, geothermal energy and tidal energy. Emergy analysis ignores the fourth basic resource of energy, namely nuclear energy, because nuclear energy will not naturally appear in the existing environment. The basic idea of emergy analysis is to identify the chain system and determine the energy value accumulated from the initial. In the calculation method, the quantifiable value of the quality or heat of any product or service can be multiplied by its energy value per unit value. When studying the evolution of urban emergy, the calculated emergy flow can be incorporated into the urban metabolic model, and the characteristic equation of the city can be determined by studying the change of flow stock. In this theory, emergy is defined as the quantity of another kind of energy contained in a unit product or service. Because all kinds of energy contained in the system come from solar energy, we can use the quantity of solar energy as the dimension to measure any form of material and energy. The specific emergy calculation method is as follows:

$$
E_{m}=\sum M_{i} \times U E V_{i}
$$

where, $E_{m}$ represents the emergy, sej; $M_{i}$ is the quantity of $\mathrm{i}$-th type flow of material or energy, $\mathrm{g}, \mathrm{J}$ or $\$$; $\mathrm{UEV}_{\mathrm{i}}$ is the unit emergy value of i-th flow, sej/g, sej/J, sej/\$.

The flowing resources in urban ecosystem can be divided into four types: Renewable resources (R), Nonrenewable resources and products (N), Imports (I) and Exports (E) [6]. The renewable resources refer to the flow of solar energy contained in locally owned renewable resources and includes Solar energy, kinetic energy of wind, geopotential energy and chemical potential energy of rain. The nonrenewable resources and products refer to the flow of solar energy contained in locally owned nonrenewable resources and include mineral resources, fossil energy, pesticides, fertilizers and topsoil loss. The imports refer to the energy value of imported resources in the system, such as labor, electricity, coal, and natural gas. The exports refer to the products and services exported in the system and tourism income. In addition, the global emergy baseline applied in our study is $15.83 \times 10^{24} \mathrm{sej} / \mathrm{yr}$. [7] .

Moreover, this study established emergy yield rate (EYR), emergy load rate (ELR) and emergy sustainability index (ESI) to evaluate the sustainability of cities [8]. EYR is the ratio of system output emergy to economic feedback emergy and could represent the capability of a production process to exploit local resources. ELR refers to the ratio of non-renewable resources to the total emergy value of product inputs and the total emergy value of renewable energy inputs. The higher the value of ELR, the higher load on the ecosystem. ESI is the ratio of EYR to ELR, and It is used to comprehensively evaluate the sustainable development performance of the area.

\subsection{Research area and data acquirement}

Located in the lower reaches of the Yellow River, Shandong Province is one of the main coastal provinces in eastern China, with a total land area of 156700 square kilometres, accounting for about $1.60 \%$ of the total area of the country. By the end of 2019 , the total population of Shandong Province will reach 100.7 million, which is the second most populous province after Guangdong Province. Shandong Province, as the frontier province of China's opening up, actively participates in international competition, especially after the financial crisis. With the accelerating process of economic integration, the global economic structure has entered an important transformation stage. Shandong Province is facing a more complex and severe situation. At the same time, it also creates favourable conditions for Shandong Province to try the "going out" strategy. In 2018, the total economic volume of Shandong reached 7.65 trillion, with a nominal growth rate of $8.64 \%$, ranking the third in China. However, the economic development of Shandong is facing downward pressure, and there are various problems in the mode of economic development, such as the high cost of energy consumption, the economic structure to be adjusted and optimized, and the weak ability of independent innovation. These problems seriously restrict the quality of economic growth in Shandong province. At the same time, Shandong province is in an important period of changing the mode of economic development. It is of great significance to make full use of its superior geographical position and the advantages of foreign direct investment to achieve high-quality economic development in Shandong Province. Raw data of different flows, GDP, and population for the period 2008-2018 were obtained from Shandong statistical yearbook, statistical communique of economic and social development of Shandong, and China urban construction statistical yearbook.

\section{Results and discussion}

\subsection{The emergy of the urban ecosystem}

The total emergy used in Shandong province increased from $1.31 \times 10^{24}$ sej in 2008 to $2.18 \times 10^{24}$ sej in 2018 according to Table 1 . Among them, the emergy values of renewable resources remain unchanged and the emergy values of non-renewable resources and products gradually decrease from $6.41 \times 10^{23} \mathrm{sej}$ in 2008 to $5.43 \times 10^{23} \mathrm{sej}$ in 2018). However, the imported emergy has risen sharply from $6.53 \times 10^{23}$ sej in 2008 to $1.62 \times 10^{24}$ sej in 2018 . At the same time, the emergy used proportion of nonrenewable 
resources and products gradually decreased $(24.98 \%$ in 2018 ), and the emergy used proportion of imports gradually increased $(74.45 \%$ in 2018). Therefore, the development model of Shandong province has shifted from relying on the exploitation of local resources to

Table 1 Emergy-based accounting results and indices of Shandong province from 2008 to $2018\left(10^{23}\right.$ sej).

\begin{tabular}{|c|c|c|c|c|c|c|c|c|}
\hline Year & $\mathbf{R}$ & $\mathbf{N}$ & $\mathbf{I}$ & $\mathbf{E}$ & $\mathbf{U}$ & $\mathbf{E Y R}$ & $\mathbf{E L R}$ & $\mathbf{E S I}$ \\
\hline 2008 & 0.12 & 6.41 & 6.53 & 5.39 & 13.06 & 2.00 & 103.99 & 0.02 \\
\hline 2009 & 0.12 & 6.39 & 6.71 & 4.53 & 13.23 & 1.97 & 105.32 & 0.02 \\
\hline 2010 & 0.12 & 6.66 & 9.19 & 6.92 & 15.98 & 1.74 & 127.47 & 0.01 \\
\hline 2011 & 0.12 & 6.75 & 9.67 & 7.32 & 16.54 & 1.71 & 131.99 & 0.01 \\
\hline 2012 & 0.12 & 7.04 & 10.54 & 8.13 & 17.70 & 1.68 & 141.29 & 0.01 \\
\hline 2013 & 0.12 & 6.67 & 12.12 & 10.32 & 18.91 & 1.56 & 151.04 & 0.01 \\
\hline 2014 & 0.12 & 6.64 & 12.75 & 11.19 & 19.51 & 1.53 & 155.85 & 0.01 \\
\hline 2015 & 0.12 & 6.34 & 13.45 & 11.64 & 19.91 & 1.48 & 159.06 & 0.01 \\
\hline 2016 & 0.12 & 6.02 & 14.25 & 11.42 & 20.39 & 1.43 & 162.92 & 0.01 \\
\hline 2017 & 0.12 & 5.92 & 15.53 & 13.01 & 21.58 & 1.39 & 172.44 & 0.01 \\
\hline 2018 & 0.12 & 5.43 & 16.20 & 13.05 & 21.75 & 1.34 & 173.88 & 0.01 \\
\hline
\end{tabular}

\subsection{Urban sustainability assessment}

Odum identified natural capital and ecosystem services as the real source of wealth from the donor side. This method can put aside the specific material composition, structural characteristics and connection forms of the ecosystem, and take energy as the general currency, which makes the connection between life and non-life costs become a functional whole system that performs ecological functions through energy and reflects ecological relations. In order to evaluate the sustainability of urban development, emergy method establishes a series of indicators to evaluate the sustainability. Emergy yield rate is the ratio of total energy consumption to import energy consumption, which indicates the effectiveness of system economic investment. Through the comparison of EYR, we can understand the dependence of different systems on local resources or imported goods [9]. The higher the value of EYR, the higher the development capacity of local renewable or non-renewable resources. Of course, if we use renewable resources, this process is sustainable. If we overexploit non-renewable resources, it will be an unsustainable process. In this study, the EYR of Shandong decreased from 2.00 in 2008 to 1.34 in 2018, which indicates that more and more resources are driving the urban development and Shandong province largely relied on local resources.

Emergy load rate is the ratio of the sum of local nonrenewable resources and emergy of products and purchased emergy (including services) to emergy of local renewable resources. This index shows the indirect contribution of environmental resources to the whole system. The smaller the environmental carrying capacity is, the greater the dependence on renewable resources is. For example, a complete natural ecosystem depends entirely on the input of renewable resources. At the same relying on importing resources to promote the development of the city's economy, nature and society and to keep the emergy of exports increasing by the emergy of exports. 
burden and should promote industry transformation and accelerate industrial upgrading. Therefore, Shandong province should adjust the industrial structure and give full play to the advantages of local resources. Shandong province can vigorously develop marine economic industry and give full play to the advantages of marine ecological resources of coastal cities. Secondly, renewable resources should be used to replace the nonrenewable resources used in industry, and the backward industries should be eliminated, the combustion and use of fossil fuels should be reduced, and the clean energy industry should be continuously introduced. At the same time, Shandong can readjust the input-output ratio of local economic resources and optimize the industrial chain. In the economic system, Shandong should pay attention to the relationship between the input and output of local departments and industries, pay attention to whether the allocation of resources among various factors is reasonable, pay attention to the growth mode of efficiency and introduce advanced technology, so as to properly replace the imported nonrenewable resources and improve the utilization rate of energy.

\section{Conclusion}

This study uses the emergy method to calculate the inputs and outputs of Shandong and establishes an emergy indices to evaluate the performance of sustainable development. The results show that total emergy used in Shandong increased from $1.31 \times 10^{24} \mathrm{sej}$ in 2008 to $2.18 \times 10^{24}$ sej in 2018 and more and more resources are invested to promote the development of Shandong. However, the efficiency of this development method is low and the pressure on the city's ecological environment is relatively high according to the emergy sustainable index, which has led to the low sustainability of urban development.

\section{References}

1.Brown, M.T., et al., Species diversity in the Florida Everglades, USA: A systems approach to calculating biodiversity. 2006. 68(3): p. 254-277.

2.Castellini, C., et al., Sustainability of poultry production using the emergy approach: Comparison of conventional and organic rearing systems. 2006. 114(2): p. 343-350.

3.Oliveira, J.H., et al., Decision making under the environmental perspective: Choosing between traditional and distance teaching courses. Journal of Cleaner Production, 2018. 172: p. 4303-4313.

4.Li, J.-X., et al., Evaluation and analysis of ecological security in arid areas of Central Asia based on the emergy ecological footprint (EEF) model. Journal of Cleaner Production, 2019. 235: p. 664-677.

5.Wu, X., et al., Emergy-based sustainability assessment of an integrated production system of cattle, biogas, and greenhouse vegetables: Insight into the comprehensive utilization of wastes on a large-scale farm in Northwest China. 2013. 61(19): p. 335-344.

6.Li, T., Y. Song, and J. Shen, Clean Power Dispatching of Coal-Fired Power Generation in China Based on the Production Cleanliness Evaluation Method. Sustainability, 2019. 11(23).

7.Barros, D.E., et al., Emergy evaluation and economic performance of banana cropping systems in Guadeloupe (French West Indies). 2009. 129(4): p. 437449.

8.Huang, S.L., W.L.J.L. Hsu, and U. Planning, Materials flow analysis and emergy evaluation of Taipei's urban construction. 2003. 63(2): p. 61-74.

9.Cao, K. and X. Feng, The Emergy Analysis of MultiProduct Systems. Process Safety and Environmental Protection, 2007. 85(5): p. 494-500.

10.Brown, M.T., M. Raugei, and S. Ulgiati, On boundaries and 'investments' in Emergy Synthesis and LCA: A case study on thermal vs. photovoltaic electricity. Ecological Indicators, 2012. 15(1): p. 227235.

11.Zhang, X., et al., Identification and Genetic Division of Fusarium graminearum and Fusarium asiaticum by Species-Specific SCAR Markers. Journal of Phytopathology, 2014. 162(2): p. 81-88. 